\title{
Supply and Distribution of Primary Healthcare Registered Nurses in British Columbia
}

\section{Effectif et distribution des infirmières autorisées œuvrant dans les soins primaires en Colombie-Britannique}

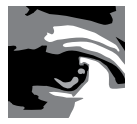

by SABRINA T. WONG, RN, PHD

Assistant Professor, School of Nursing Culture, Gender and Health Research Unit Centre for Health Services and Policy Research

University of British Columbia

Vancouver, BC

DIANE E. WATSON, MBA, PHD

Centre for Health Services and Policy Research

University of British Columbia

Vancouver, BC

ELLA YOUNG, MHA

Research Coordinator, Centre for Health Services and Policy Research

University of British Columbia

Vancouver, BC 
Sabrina T. Wong et al.

DAWN MOONEY, BA

Geographer, Centre for Health Services and Policy Research

University of British Columbia

Vancouver, BC

\begin{abstract}
What did we do? This study uses an existing data source to (a) describe the population and geographic distribution of registered nurses (RNs) working in primary healthcare (PHC) in British Columbia, (b) compare this workforce to PHC physicians and (c) assess the distribution of PHC-RNs relative to population health status.
\end{abstract}

What did we learn? Of the 27,570 practising RNs in British Columbia in 2000, there were 3,179 (12\%) in the PHC workforce. This translates into 147 people per practising $\mathrm{RN}$ and 1,277 people per PHC-RN. In 2000, there were 990 people per PHC physician. PHC-RNs represented $43 \%$ of the combined PHC workforce of physicians and RNs. A large proportion (47\%) of PHC-RNs worked in community health centres, whereas less than $2 \%$ worked in physicians' offices. Geographic distribution of PHC-RNs is similar to the distribution of PHC physicians and is not associated with population health status.

What are the implications? There seem to be sufficient PHC-RNs to implement policy objectives in support of interdisciplinary PHC teams, but physicians and nurses will increasingly need to practice in the same location or have access to electronic information systems to support coordination, continuity and comprehensiveness of PHC. The PHC workforce could be better deployed to align with population health status.

\title{
Résumé
}

Ce que nous avons fait: Cette étude utilise une source existante de données pour (a) décrire la population et la distribution géographique des infirmières autorisées qui travaillent dans le contexte des soins de santé primaires (SSP) en Colombie-Britannique, (b) comparer cette main-d'œuvre avec celle des médecins qui œuvrent dans les SSP et (c) évaluer la distribution des infirmières autorisées en fonction de létat de santé de la population.

Ce que nous avons appris: Parmi les 27570 infirmières autorisées de la ColombieBritannique en 2000, 3179 (12\%) travaillaient dans le secteur des SSP. Cela se traduit par 147 personnes pour chaque infirmière autorisée et 1277 personnes pour chaque infirmière autorisée œuvrant dans les SSP. En 2000, il y avait 990 personnes pour chaque médecin travaillant dans les SSP. Les infirmières autorisées œuvrant dans 
les SSP représentaient $43 \%$ de la main-d'œuvre des SSP, comprenant à la fois les infirmières et les médecins. Une grande proportion (47\%) des infirmières autorisées œuvrant dans les SSP travaillaient dans des centres de santé communautaire tandis que moins de $2 \%$ travaillaient dans des cabinets de médecins. Dans le contexte des SSP, la distribution géographique des infirmières autorisées est semblable à celle des médecins et ná pas de lien avec létat de santé de la population.

Répercussions : Il semble y avoir, dans les SSP, suffisamment d'infirmières autorisées afin de réaliser les objectifs politiques d'appui aux équipes interdisciplinaires de SSP, mais les médecins et les infirmières devront de plus en plus travailler dans les mêmes lieux ou avoir accès à des systèmes d'information électronique afin d'assurer la coordination, la continuité et l'intégralité des SSP. Dans les SSP, la main-d'œuvre pourrait être mieux déployée afin de s'harmoniser avec l'état de santé de la population.

\section{$\boldsymbol{I}_{\text {he Canadian federal and provincial/territorial governments }}$ have channeled substantial investment into primary healthcare (PHC) \\ 1 renewal in an attempt to ensure that $50 \%$ of the population have 24 -hour} access, seven days a week to multidisciplinary PHC teams by 2011 (Government of Canada 2006a,b, 2007). In 2004, the First Ministers agreed to accelerate work on health human resources (HHR) planning and initiatives to ensure an appropriate mix and adequate supply of healthcare professionals. Since that time, jurisdictions have developed a pan-Canadian framework for HHR planning that takes population health needs into account in order to design more responsive health systems (Federal/ Provincial/Territorial Advisory Committee 2005). By 2007, approximately 40\% of adults in Canada reported having access to PHC teams of doctors, nurses and/or other health professionals and access is most common among individuals with two or more chronic conditions (Khan et al. 2008).

While more work is needed to develop appropriate theories and methods to assess the distribution of registered nurses (RNs) relative to population health needs and the provision of $\mathrm{PHC}$, foundational work describing the aggregated supply, distribution and deployment of RNs has been completed (Birch et al. 2007; O'Brien-Pallas et al. 2003). Past research has described, for example, the supply and distribution of RNs by geographic location or by using the categories of age, employment and place of work separately (CIHI 2004, 2006). Yet, in the area of PHC, little is known about the relative number and distribution of RNs who work in this sector, the distribution of this workforce across geographic regions relative to population health status or the degree to which existing information systems can be used to describe the PHC-RN workforce.

The objectives of this study were to (a) describe the population and geographic 
distribution of RNs who deliver PHC in British Columbia in the year prior to major investment to catalyze renewal of this sector, (b) compare the size of this workforce relative to PHC physicians in the province, (c) assess the distribution of this workforce relative to population health status and (d) draw conclusions regarding the usefulness of existing data sources in identifying these health professionals. The study parallels other work by our team to identify physicians that work in PHC, describe temporal shifts in solo and group practices and assess the distribution of this physician workforce relative to population health status (McKendry et al. 2006; Watson et al. 2006).

\section{What Did We Do?}

We used RN registration data from fiscal year 2000 in order to identify PHC-RNs. Data from 2000 were used because these data (a) predate PHC renewal initiatives funded through the Primary Health Care Transition Fund (PHCTF) to create a baseline for comparison purposes and (b) permit comparison to and amalgamation with the most comprehensive and complete assessment of the size and distribution of the PHC physician workforce in British Columbia.

The RN registration data are self-reported and collected annually by the College of Registered Nurses of British Columbia (CRNBC; formerly the Registered Nurses Association of British Columbia). Registration data are collected on all practising and non-practising clinicians who use the title " $\mathrm{RN}$ " in British Columbia and include such demographic information as year of birth, sex, education, practice status and employment information. All RNs are asked to state their primary, secondary and tertiary employers, including the primary employer's address. Reporting of secondary and tertiary employers' addresses is optional. We obtained anonymous registration data from the data holdings at the Centre for Health Services Policy and Research after obtaining ethics approval from the University of British Columbia; permission to use the data was granted from CRNBC.

Based on consultation with CRNBC and a small panel of RNs consisting of two community health nurses, a nurse manager and a community health nurse researcher, four variables in the registration data were used to identify PHC-RNs: place of work, area of responsibility, position and work status.

Place of work included nursing station/outpost/nurse clinic; private nursing agency/private duty; business/industry/occupational health; self-employed/private practice; mental health centre; physician's office; home care agency; and public health agency/community health centre.

Area of responsibility included rehabilitation/occupational health; mental health; home care; emergency care; and community health. Community health nurses in British Columbia carry out public health activities such as immunizations, well-baby 
care and health promotion. These RNs also provide PHC services such as wellness care (e.g., routine blood pressure checks, health education), home care and chronic disease management.

The following positions were identified as relevant because RNs who assumed these roles would have direct interactions with the public: consultant; staff nurse/ home care/community nurse; office/occupational/industrial nurse; and manager/ assistant manager/supervisor.

Only RNs indicating part-time and full-time work status were included; those working casually were excluded because it was not possible to determine how many hours were worked.

In order to understand the characteristics and geographic dispersion of the PHC$\mathrm{RN}$ workforce, we described the demographic characteristics of this group and calculated crude ratios of provider-to-population and population-to-provider. Population estimates were derived using British Columbia Statistics PEOPLE 28 (BC Ministry of Labour and Citizens' Services 2003). These ratios are compared to the ratio of population to general practitioners, family physicians and specialists deemed to be working in the PHC sector (Watson et al. 2006).

We gathered information for each of 16 health service delivery areas (HSDAs) and the 89 local health areas (LHAs), except in areas where both the total number of practising RNs and the number of PHC-RNs were very low (i.e., fewer than five $\mathrm{RNs}$ ). We assigned PHC-RNs to jurisdictions on the basis of the primary employer's work address. In cases where nurses had provided no work address, we used their home address instead. Counts of PHC-RNs were combined with counts of PHC physicians at the HSDA level to calculate crude supply ratios. We used head counts to estimate the stock of supply because full-time equivalents for the RN workforce were not available. We also calculated the ratio of PHC-RNs to PHC physicians at the HSDA level to examine how supply rates of these providers were distributed across the province.

In order to assess equity in the geographic distribution of $\mathrm{PHC}$ providers, we measured the association of the supply-to-population ratio relative to the health status of those who resided in the same HSDA. The age and sex standardized premature mortality rate (PMR) was used as the central measure of need for healthcare because it is a widely accepted indicator of population health status (Birch and Eyles 1991; Shi et al. 2005). PMR is highly correlated with other measures of health in British Columbia, including potential years of life lost (Pearson correlation coefficient: $0.95, p<0.0001$ ), life expectancy (Pearson correlation coefficient: $-0.94, p<0.0001$ ) and age-standardized mortality (Pearson correlation coefficient: 0.91, $p<0.0001$ ) (McGrail et al. 2004). Pearson correlation coefficients and scatter plots were used to assess and illustrate the degree of association between the distribution of PHC-RNs and PHC physicians relative to PMR. 


\section{What Did We Learn?}

In 2000, 33,099 RNs were registered with the CRNBC and 27,570 (83\%) of these RNs were practising. This equates to a total of 679 practising RNs per 100,000 or, conversely, a total of 147 people per practising RN. Eighty-one per cent of practising RNs reported their place of work as one of three settings: a hospital $(n=17,265)$, a community health agency or centre $(n=2,498)$ or a long-term care home $(n=2,399)$.

We identified a total of 3,179 ( $12 \%$ of practising RNs) who met our eligibility criteria as working in the PHC sector. This equates to 78 per 100,000 population, or 1,277 people per PHC-RN. A large proportion (47\%) of all PHC-RNs worked in community health centres, whereas less than $2 \%$ of all PHC-RNs worked in physicians' offices.

Almost three-quarters (74\%) of PHC-RNs were either staff nurses employed in community health centres $(n=1,395)$ or emergency rooms $(n=962)$. A total of 13 staff nurses were employed in a physician's office. Figure 1 shows the PHC-RNs according to their place of work and area of responsibility; $44 \%$ were staff nurses providing either community health or home care services, another $30 \%$ were staff nurses providing emergency care in hospitals and less than $1 \%$ of PHC-RNs were staff nurses in physician offices.

FIGURE 1. PHC-RNs by place of work and area of responsibility

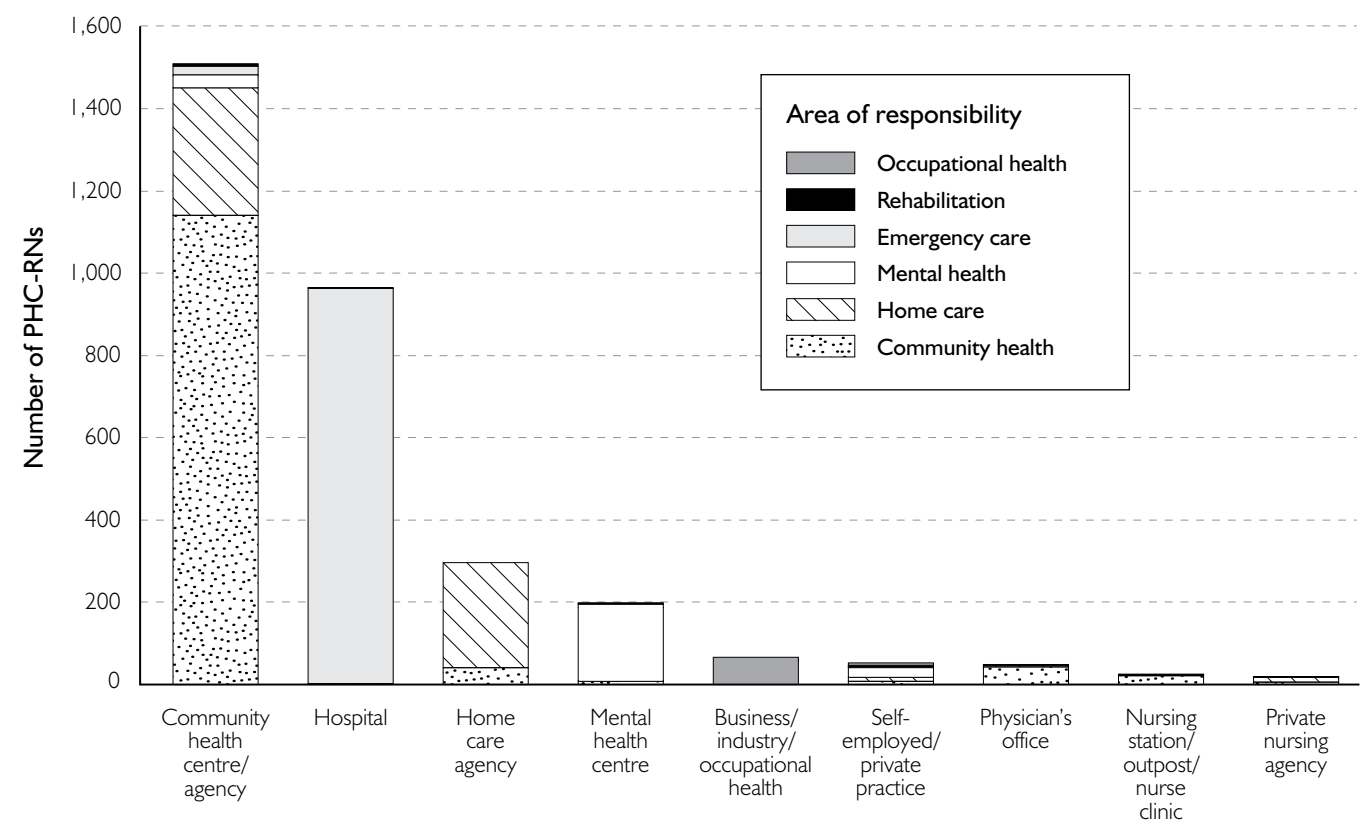

Place of work 
We identified an additional 590 "possible PHC-RNs" who reported secondary employment in PHC. The distribution of place, position and area categories of "possible PHC-RNS" was similar to those of PHC-RNs. The largest proportion $(n=183)$ of these potential PHC-RNs were staff nurses working in community health agencies providing either public health or home care services. Seventeen per cent were staff nurses working hospital emergency rooms, and $15 \%$ were staff nurses working in hospitals providing PHC services.

The majority of RNs working in PHC were female (96\%) and between the ages of 40 to 59 years (70\%). One-quarter were under 40 years; only $5 \%$ were 60 years and older. The median age of PHC-RNs was 46 years, one year older than all other practising RNs in British Columbia. Almost half (49\%) worked full-time and 35\% worked part-time in a PHC role for their primary employer. Across HSDAs, the PHC-RN to population ratio varied from a high of 119 per 100,000 in Kootenay Boundary to a low of 56 per 100,000 in Fraser South. Across LHAs this ratio varied from a high of 244 per 100,000 in Castlegar to a low of zero in Arrow Lakes.

Combining counts of all RNs and physicians working in PHC in British Columbia in 2000 resulted in a crude ratio of 180 per 100,000 people. There was a twofold variation across HSDAs, with a high of 261 per 100,000 people in Vancouver to 125 per 100,000 in Fraser South. Figure 2 reveals some variation in the distribution of PHC-RNs per 100,000 population and more variation in the distribution of PHC physicians per 100,000 population. Regions reporting a relatively high ratio of PHC-RNs to population tended also to report a higher ratio of PHC physicians to population. The maps, or cartograms, in Figure 2 show British Columbia's HSDAs proportionally sized by their populations instead of by the size of the geographic area.

Although PHC-RNs accounted for $12 \%$ of the $\mathrm{RN}$ workforce, they accounted for almost half (43\%) of the combined PHC physician and PHC-RN workforce. Figure 3 shows that the percentage of the PHC-RNs of the combined PHC physician and $\mathrm{RN}$ workforce was similar across urban and rural regions.

If $\mathrm{PHC}$ providers were equitably distributed across the province according to population health status, we could expect that areas with low population health status (high PMR) would have a higher stock of providers to meet the areas' additional needs. Conversely, areas with high population health status (low PMR) would have a lower stock of providers. That is, we would expect a significant positive association between measures of supply and PMR. Yet, we found no association between PHC-RN supply and British Columbians' health status in 2000 (Pearson correlation coefficient: $0.48, p=0.06$ ). Communities with lower levels of health did not have more PHC-RNs, and communities with higher levels of health did not have fewer PHC-RNs. Figure 4 shows that that there was also no strong association between population health status and the combined stock of PHC-RN and PHC physicians (Pearson correlation coefficient: $0.33, p=0.21$ ). 
FIGURE 2. Variation in supply of PHC-RNs and PHC physicians by health service delivery area

Crude Ratio of PHC RNs per 100,000 Population

2000

Kootenay Boundary

South Island

Northwest

Vancouver

North Island

Thompson Cariboo

Okanagan

Central Island

Northeast

Northern Interior

N. Shore/Coast Gar.

Fraser East

Fraser North

Richmond

East Kootenay

Fraser South
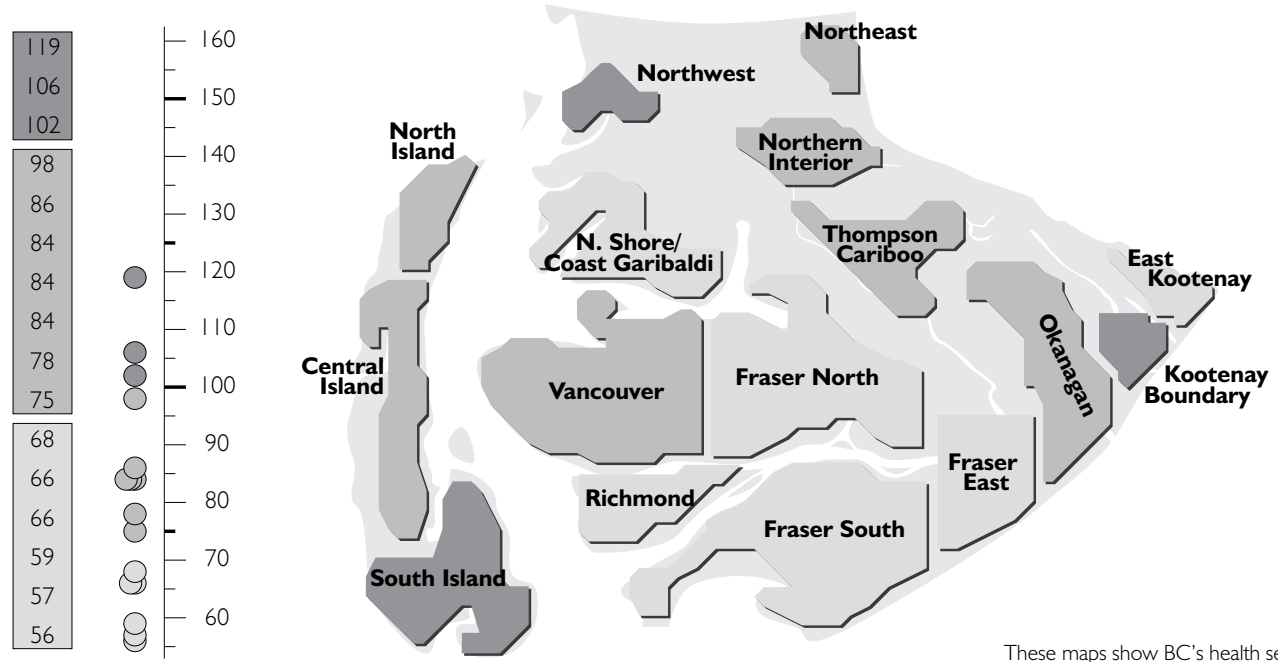

These maps show BC's health service delivery areas sized by their population instead of their area. Shape and contiguity are preserved as much as possible. An

Crude Ratio of PHC Physicians per 100,000 Population 2000/01

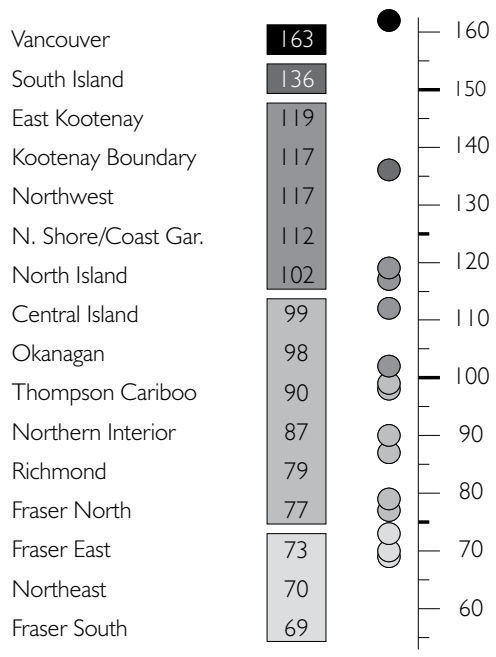

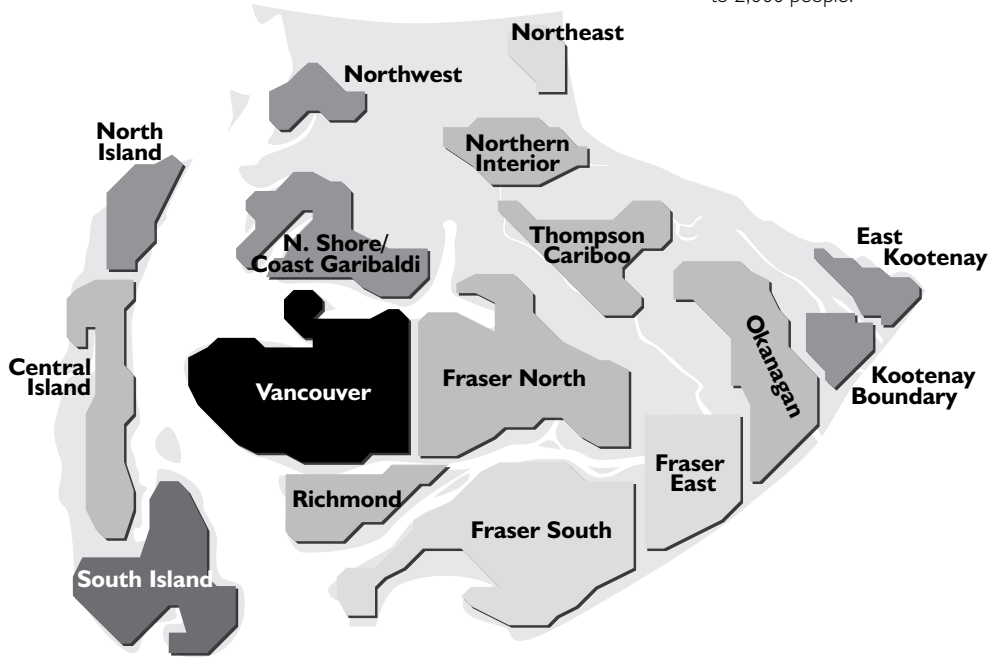

Data for both maps are classified into equal intervals as follows: <75, 75-99, 100-124, 125-149, I50+.

RN counts: Registration Database (2000), CRNBC.

Physician counts: MSP practitioner information file, MSP payment information master file (for fee-for-service data), hospital, primary healthcare organizations and alternative payments to physicians data, all BC Ministry of Health 2000/0I data; CPSBC (2000/0 I).

Population counts: PEOPLE 28 (2000), BC Stats.

\section{What Are the Implications?}

There were 27,570 practising RNs in British Columbia in 2000. Similar ratios of supply to population in this province have been reported by the Canadian Institute for 
Health Information (CIHI 2001). We now know that PHC-RNs represent approximately $12 \%$ of the total supply of practising RNs, and that the proportion of $\mathrm{PHC}$ RNs in British Columbia appears similar to that in Ontario, as estimated in a recent research project (Moira Stewart, Director, Centre for Studies in Family Medicine, personal communication, October 2006). More recently, we undertook similar work to calculate the size and geographic distribution of practising RN and PHC-RNs workforce in 2006. The proportion of PHC-RNs remains relatively unchanged, despite substantive increases in the RN workforce between 2000 and 2006 (Watson et al. 2009).

FIGURE 3. Combined ratios of PHC-RNs and PHC physicians by health service delivery area and by approximate urban/rural status

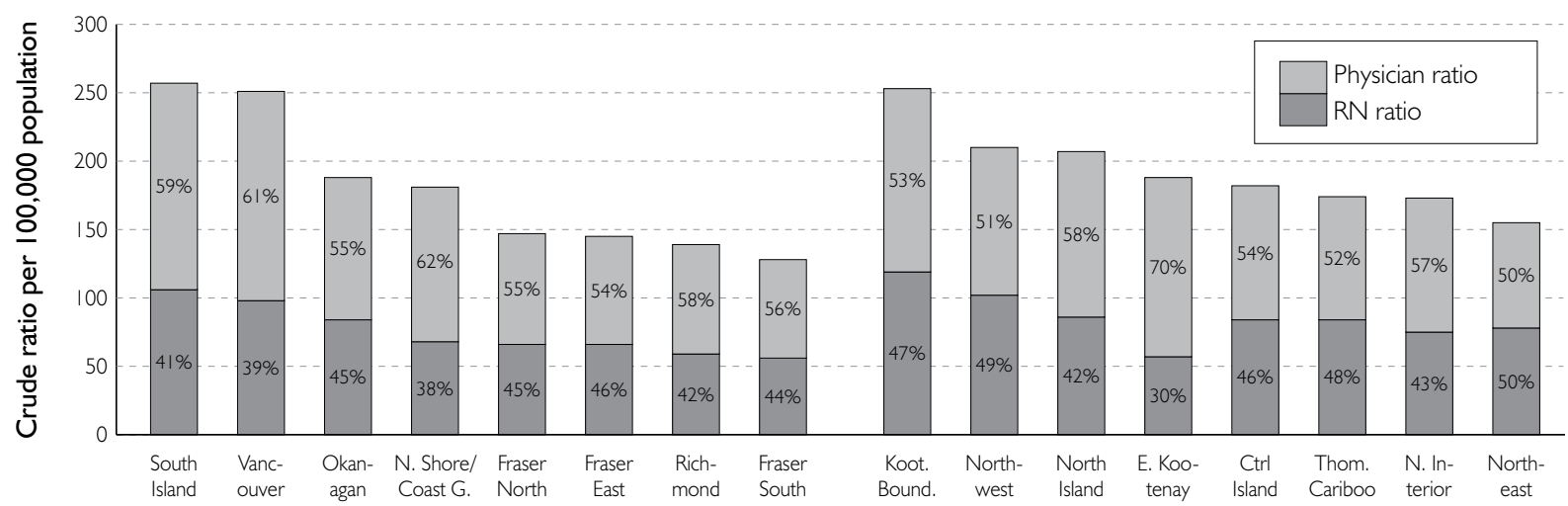

More urban health service delivery areas

More rural health service delivery areas

RN counts: Registration Database (2000), CRNBC.

Physician counts: MSP practitioner information file, MSP payment information master file (for fee for service data), hospital, primary healthcare organizations and alternative payments to physicians data, all BC Ministry of Health 2000/0 I data; CPSBC (2000/0 I).

Population counts: PEOPLE 28 (2000), BC Stats.

If $12 \%$ of all 232,000 RNs across Canada in 2000 (CIHI 2001) worked in PHC, there would be 76 PHC-RNs per 100,000 population, or 1,327 people per PHCRN. In British Columbia, this level of supply translates into 1,277 people per PHC$\mathrm{RN}$, suggesting a relatively higher level of supply than elsewhere in Canada due to the higher number of practising RNs to population in British Columbia.

By comparison, the supply of PHC physicians in British Columbia was slightly higher than that of PHC-RNs, at 101 per 100,000 or 990 people per PHC physician (Watson et al. 2006). These results suggest a level of supply (approximately one PHC-RN and one physician per 1,000 people) that has face validity of sufficiency in terms of the number active in provision of PHC. Clearly, work is needed to determine the extent of a shortage or surplus in the supply of healthcare providers who work in 
the PHC sector, and the factors influencing perceptions of workforce sufficiency.

FIGURE 4. Combined ratio of PHC-RNs and PHC physicians by premature mortality rate

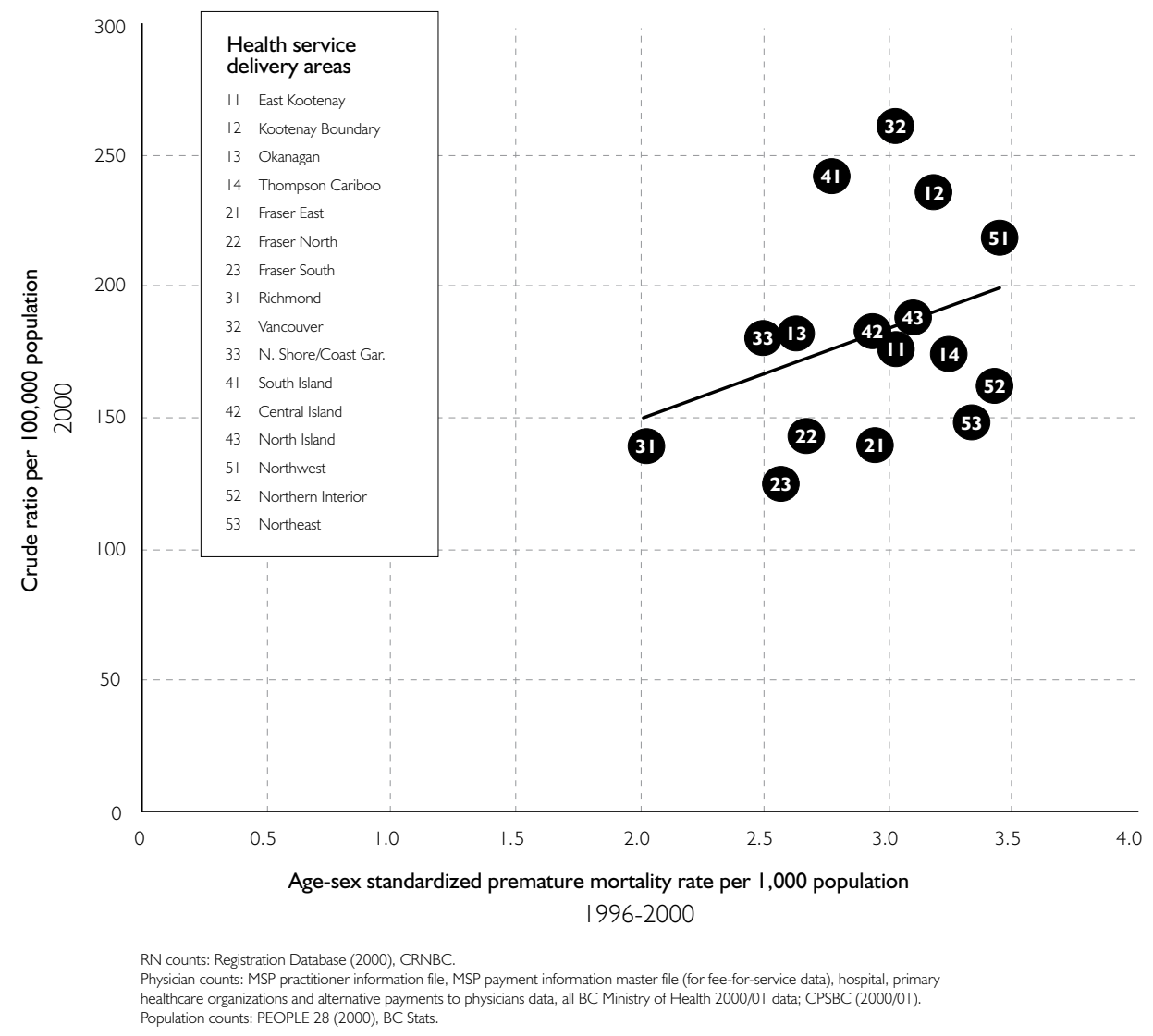

We contribute to the HHR planning agenda by offering new evidence regarding the number of RNs currently working in $\mathrm{PHC}$, the proportion active in the provision of $\mathrm{PHC}$ and the geographic distribution of these providers relative to population health status. Needs-based planning for this sector will require more research to assess the productivity of this PHC workforce, as well as factors (e.g., organization of care) that influence production, utilization, effectiveness and efficiency (Birch et al. 2007).

Our findings offer insights regarding the organization of care relative to public policy objectives to improve access and quality of PHC, and ultimately population health status, through increases in use of multidisciplinary teams. Importantly, most PHC-RNs (47\%) worked at community health centres in 2000, but only $3.9 \%$ of general practitioners and family physicians in British Columbia reported such locations as their main practice setting in 2001 (College of Family Physicians of Canada 2001). Conversely, few PHC-RNs (2\%) worked in physicians offices in 2000, while $83 \%$ of 
general practitioners and family physicians in British Columbia reported this location as their main practice setting in 2001. These data suggest that PHC physicians and RNs tend to deliver services in different workplace settings to different patients. Indeed, the national work by MacLeod and colleagues (2004) suggests that many PHC-RNs working in rural and remote Canada work alone or with little back-up in their everyday practice. There is less empirical evidence about the extent to which patient care is coordinated or delivered by both PHC-RNs and physicians in more urban areas of British Columbia. Insofar as co-location is a precondition to multidisciplinary collaborative practice, particularly when electronic information systems that enable teams to transcend geography are relatively rare in Canada (Schoen et al. 2006), much could be done to improve the organization and location of providers and support teams that collaborate to meet population needs. PHC teams improve processes of care, reduce emergency room use, reduce risk of hospitalization and enhance confidence in the healthcare system (Barrett et al. 2008; Khan et al. 2008).

We determined that the geographic distribution of PHC-RNs does not optimally align with population health status. Our metric of supply-to-population ratio presumes that providers deliver care to populations that reside in the same location. Previous work by our team documents disparities in geographic distribution of PHC physicians in British Columbia but reports equity in the utilization of PHC physician services (Watson et al. 2005). In combination, these results suggest that patients or PHC physicians (or both) move across jurisdictional boundaries to obtain or deliver needed PHC services. The same could be true with regard to PHC-RNs. The degree to which patients or RNs move across boundaries to receive or deliver PHC services will remain unknown until information systems are designed to link PHC-RN services to the health status of their patients.

It is important to acknowledge that population-based administrative data sources are not sufficiently developed to describe the degree to which RNs or physicians deliver all core functions of $\mathrm{PHC}$ - first-contact care and services considered to be responsive, comprehensive, continuous and coordinated. Although some studies have described the work of PHC-RNs (Andrews et al. 2005; Clarke and Mass 1998; Wong et al. 2006), more work is needed to examine the degree to which PHC-RNs are involved in delivering the core functions of $\mathrm{PHC}$ or enacting the principles of PHC across geographic regions. This aim could be accomplished through additional analyses of college registration data, future inclusion of questions addressing nursing roles and functions on college registration forms or both. Alternatively, questions could be included in provincial or nationwide surveys of nurses to determine the degree to which they engage in delivering PHC services.

Our study should be interpreted in light of its limitations. Specifically, the methods we developed to identify PHC-RNs did not include all RNs who deliver some PHC services as a portion of their day-to-day work. The result of this type of meas- 
urement error is that we underestimate the quantity of PHC services delivered by PHC-RNs. Next, geographic-based analyses rely on the completeness and accuracy of self-reported data regarding primary employer location. The data included more than one address, depending on the number of employers, for each RN. Thus the challenge was to situate each RN within a geographic location where she or he delivers most PHC services, despite the fact that some RNs work at more than one geographic region. This type of measurement error is likely to be random in urban or rural areas and, therefore, should not bias estimates of equity in distribution relative to population need. Lastly, definitive conclusions about causal relationships between geographic distribution of the PHC-RN workforce and population health status cannot be made because of the cross-sectional study design.

\section{Recommendations}

This study provides baseline information about the supply and distribution of PHCRNs working in British Columbia using newly developed methods that can be applied to current data and in other jurisdictions. Further research is needed to examine the nature of PHC-RNs practice, determine whether there is a shortage or surplus of PHC-RNs, and consider how PHC services might be better organized so that providers can work collaboratively in the same settings towards improving access and quality and optimally aligning with population needs. Indeed, policy and planning activities related to PHC will require more up-to-date information that includes other health professionals (e.g., nurse practitioners, nutritionists, dentists, social workers, pharmacists) who work in this sector.

\section{ACKNOWLEDGEMENTS}

This study was made possible by a grant from the Michael Smith Foundation for Health Research (MSFHR) to support new faculty research at the University of British Columbia. Dr. Wong was also supported by a career award from the National Institute of Aging (NIA) (444918-31259) and a scholar award from MSFHR. We would like to acknowledge the College of Registered Nurses of British Columbia (CRNBC) for access to anonymized registration data and assistance in the interpretation of how the data were coded. Martha MacLeod, Charlyn Black, Alba DiCenso and Sandra Regan provided valuable feedback on drafts of this manuscript, and Rachael McKendry and Peter Schaub contributed to validation work to assign registered nurses to geographic areas. The British Columbia Ministry of Health Services provided some of the funding for the special issue in which this paper is published. 
Supply and Distribution of Primary Healthcare Registered Nurses in British Columbia

Conclusions are those of the authors and reflect no official endorsement by MSFHR, the NIA or the CRNBC.

Correspondence may be directed to: Dr. Sabrina T. Wong, School of Nursing

Culture, Gender and Health Research Unit, University of British Columbia, 2211

Wesbrook Mall, T-161, Vancouver, BC V6T 2B5; tel.; 604-827-5584; fax; 604-822-

7466; e-mail: sabrina.wong@nursing.ubc.ca.

\section{REFERENCES}

Andrews, M., N. Stewart, J. Pitblado, D. Morgan, C. D’Arcy and D. Forbes. 2005."Registered Nurses Working Alone in Rural and Remote Canada." Canadian Journal of Nursing Research 37(1): 14-33.

Barrett, J., V. Curran, L. Glynn and M. Godwin. 2008. CHSRF Synthesis: Interprofessional Collaboration and Quality Primary Healthcare. Ottawa, ON: Canadian Health Services Research Foundation.

Birch, S. and J. Eyles. 1991. Needs-Based Planning of Health Care: A Critical Appraisal of the Literature. Hamilton, ON: Centre for Health Economics and Policy Analysis.

Birch, S., G. Kephart, G. Tomblin Murphy, L. O’Brien-Pallas, R. Alder and A. MacKenzie. 2007. "Human Resources Planning and the Production of Health: A Needs-Based Analytical Framework." Canadian Public Policy 33: S1-S16.

British Columbia Ministry of Labour and Citizens' Services. 2003. SubProvincial Population Projects (People 28). Victoria, BC: Author.

Canadian Institute for Health Information (CIHI). 2001. Canada's Health Care Providers. Ottawa: Author.

Canadian Institute for Health Information (CIHI). 2004. Workforce Trends of Registered Nurses in Canada, 2004. Ottawa: Author.

Canadian Institute for Health Information. (CIHI) 2006. Highlights from the Regulated Nursing Workforce in Canada, 2005. Ottawa: Author.

Clarke, H. and H. Mass. 1998. "Comox Valley Nursing Centre: From Collaboration to Empowerment." Public Health Nursing 15(3): 216-24.

College of Family Physicians of Canada (CFPC). 2001. "Profile of Family Physicians/General Practitioners in British Columbia: Results of the 2001 National Family Physician Workforce Survey." Retrieved January 6, 2009. < http://www.cfpc.ca/local/files/Programs/Janus\%20project/ NFPWS\%20Regional\%20Report-\%20BC.pdf $>$.

Federal/Provincial/Territorial Advisory Committee. 2005. A Framework for Collaborative PanCanadian Health Human Resources Planning. Retrieved January 6, 2009. <http://www.hc-sc.gc.ca/ hcs-sss/pubs/hhrhs/2007-frame-cadre/index-eng.php>.

Government of Canada. 2006a (May 8). 2003 First Ministers' Accord on Health Care Renewal. Ottawa: Health Canada. Retrieved January 6, 2009. <http://www.hc-sc.gc.ca/hcs-sss/deliveryprestation/fptcollab/2003accord/index-eng.php $>$. 
Government of Canada. 2006b (May 9). First Ministers' Meeting on the Future of Health Care 2004: A 10-Year Plan to Strengthen Health Care. Retrieved January 6, 2009. <http://www.hc-sc.gc.ca/ hcs-sss/delivery-prestation/fptcollab/2004-fmm-rpm/index_e.html >.

Government of Canada. 2007 (March 1). Primary Health Care Transition Fund. Retrieved January 6, 2000. <http://www.hc-sc.gc.ca/hcs-sss/prim/phctf-fassp/index-eng.php>.

Khan, S., K. Leeb, C. McIntosh, C. Sanmartin and D.E. Watson. 2008. Primary Health Care Teams and their Impact on Processes and Outcomes of Care. Ottawa: Statistics Canada. Health Research Working Paper Series; Catalogue No. 82-622-XIE2008002. Retrieved March 14, 2009. <http:// www.statcan.gc.ca/bsolc/olc-cel/olc-cel?catno=82-622-XIE2008002\&lang=eng >

MacLeod, M., J. Kulig, N. Stewart, J. Pitblado et al. 2004. The Nature of Nursing Practice in Rural and Remote Canada. Ottawa: Canadian Health Services Research Foundation. Retrieved January 6, 2009. <http://www.chsrf.ca/final_research/ogc/pdf/macleod_final.pdf >.

McGrail, K., P. Schaub and C. Black. 2004. The British Columbia Health Atlas (2nd ed.).

Vancouver: Centre for Health Services and Policy Research. Retrieved January 6, 2009. <http:// www.chspr.ubc.ca/node/153>.

McKendry, R., D.E. Watson, D. Goertzen, D. Mooney and S. Peterson. 2006. Single and Group Practices Among Primary Health Care Physicians in British Columbia. Vancouver, BC: Centre for Health Services and Policy Research. Retrieved March 7, 2009. <http://www.chspr.ubc.ca/ research/phc/provider/physician>.

O’Brien-Pallas, L., D. Thomas, C. Alsknis, M. Luba, A. Pagniello, K. Ray et al. 2003. Stepping to Success and Sustainability: An Analysis of Ontario's Nursing Workforce. Toronto: Nursing Effectiveness, Utilization and Outcomes Research Unit. Retrieved January 6, 2009. <http://wwwfhs.mcmaster.ca/nru/documents/Stepping\%20to\%20Success\%20and\%20Sustainability\%202003. pdf>.

Schoen, C., R. Osborn, P. Huynh, M. Doty, J. Peugh and K. Zapert. 2006. "On the Front Lines of Care: Primary Care Doctors' Office Systems, Experiences, and Views in Seven Countries." Health Affairs 25(6): 555-71.

Shi, L., J. Macinko, B. Starfield, R. Politzer and J. Xu. 2005. "Primary Care, Race, and Mortality in the US." Social Science and Medicine 61: 65-75.

Watson, D.E., C. Black, S. Peterson, D. Mooney and R. Reid. 2006. Who Are the Primary Health Care Physicians in British Columbia? Vancouver: Centre for Health Services and Policy Research. Retrieved January 6, 2009. <http://www.chspr.ubc.ca/node/435>.

Watson, D.E., H. Krueger, D. Mooney and C. Black. 2005. Planning for Renewal: Mapping Primary Health Care in British Columbia. Vancouver: Centre for Health Services and Policy Research. Retrieved January 6, 2009. <http://www.chspr.ubc.ca/research/phc/mapping>.

Watson, D.E., D. Mooney, R. McKendry, D. Martin, S. Regan and S.T. Wong. On the Road to Renewal: Mapping Primary Health Care in British Columbia. Vancouver, BC: Centre for Health Services and Policy Research; March 2009. Retrieved April 2, 2009. <http://www.chspr.ubc.ca/ files/publications/mphc/mphc/update/pdfs/PHCnurses.pdf>

Wong, S.T., D.E. Watson, E. Young, D. Mooney and M. MacLeod. 2006. Who Are the Primary Health Care Registered Nurses in British Columbia? Vancouver, BC: Centre for Health Services and Policy Research. Retrieved January 6, 2009. <http://www.chspr.ubc.ca/research/phc/provider/ nurses $>$. 